\title{
Zttinerarius Reflectionis
}

\section{ESBOÇOS EPISTEMOLÓGICOS EM PSICOPEDAGOGIA CLÍNICA NO BRASIL}

\author{
Hamilton Viana Chaves. ${ }^{1}$ hamilton@unifor.br \\ Jesus Garcia Pascual² garciapascual2001@ yahoo.com.br
}

Resumo: As práticas psicopedagógicas são relativamente novas no território brasileiro. Datam da década de 1960 e foram trazidas a esta pátria por profissionais e estudiosos argentinos. O objetivo de nossa pesquisa foi traçar um percurso epistemológico da psicopedagogia clínica no Brasil para tentar compreender os pilares científicos que a sustentam, a fim de estabelecer suas bases. A partir de um levantamento prévio de autores a serem investigados, passamos à fase de leitura e análise dessas obras. Nossa investigação seguiu por duas vias de análise: a primeira delas foi construir uma epistemologia da teoria à prática psicopedagógica. Por esta primeira via, o percurso se mostrou um pouco confuso. Partindo dessa dificuldade, passamos a investigar as diversas práticas psicopedagógicas e a partir de uma segunda via, ou seja, analisamos as práticas para só então pensarmos em suas teorias. Por esse caminho tivemos condições de traçar um trajeto da epistemologia da Psicopedagogia Clínica no Brasil. Compreendemos que por seu caráter de uma nova prática nas questões de problemas de aprendizagem e, por ser altamente tributária da psicologia, da pedagogia, da psicanálise etc., a psicopedagogia ainda tem de dar muitos passos no sentido de sua afirmação epistemológica.

Palavras-chave: Epistemologia da psicopedagogia. Prática e teoria psicopedagógica. Interdisciplinaridade

\begin{abstract}
The psychopedagogical practices are relatively new in Brazil. Date of the 1960s and were brought to this country by professionals and scholars from Argentina. The goal of our research was to establish an epistemological path of the psychopedagogical clinic in Brazil to try to understand the scientific pillars that support it, in order to establish their bases. From a prior survey of authors to be investigated, we move to the stage of reading and analysis of these works. Our investigation followed by a two-way analysis: the first was to construct an epistemology of psychopedagogical theory to practice. For this first via, the course of action was a bit confusing. From this difficulty, we started to investigate the various psychopedagogical practices and started a second analysis via that means, we first analyzed the practices and only then thought of their theories. Following this way we were able to outline a trajectory of the epistemology of Psychopedagogy Clinic in Brazil. We understand that for its character of a new practice in matters of learning problems and for being highly dependent on Psychology, Pedagogy, Psychoanalysis etc., Psychopedagogy still has to reach many steps in the sense of its epistemological affirmative.
\end{abstract}

Key-words: Epistemology of the Psychopedagogy. Practice and theory Psychopedagogical. Interdisciplinary.

\footnotetext{
${ }^{1}$ Hamilton Viana Chaves. Doutorando em Educação, Professor Curso de Psicologia da UNIFOR e Psicólogo do IFCE.

${ }^{2}$ Jesus Garcia Pascual. Doutor em Educação, Professor da Graduação e Mestrado do Departamento de Psicologia da UFC
} 


\title{
Ztherarius Reflectionis
}

ESBOÇOS EPISTEMOLÓGICOS EM PSICOPEDAGOGIA

CLÍNICA NO BRASIL

\author{
Hamilton Viana Chaves, Jesus Garcia Pascual
}

Resumo: As práticas psicopedagógicas são relativamente novas no território brasileiro. Datam da década de 1960 e foram trazidas a esta pátria por profissionais e estudiosos argentinos. O objetivo de nossa pesquisa foi traçar um percurso epistemológico da psicopedagogia clínica no Brasil para tentar compreender os pilares científicos que a sustentam, a fim de estabelecer suas bases. A partir de um levantamento prévio de autores a serem investigados, passamos à fase de leitura e análise dessas obras. Nossa investigação seguiu por duas vias de análise: a primeira delas foi construir uma epistemologia da teoria à prática psicopedagógica. Por esta primeira via, o percurso se mostrou um pouco confuso. Partindo dessa dificuldade, passamos a investigar as diversas práticas psicopedagógicas e a partir de uma segunda via, ou seja, analisamos as práticas para só então pensarmos em suas teorias. Por esse caminho tivemos condições de traçar um trajeto da epistemologia da Psicopedagogia Clínica no Brasil. Compreendemos que por seu caráter de uma nova prática nas questões de problemas de aprendizagem e, por ser altamente tributária da psicologia, da pedagogia, da psicanálise etc., a psicopedagogia ainda tem de dar muitos passos no sentido de sua afirmação epistemológica.

Palavras-chave: Epistemologia da psicopedagogia. Prática e teoria psicopedagógica. Interdisciplinaridade

1.

Abstract: The psychopedagogical practices are relatively new in Brazil. Date from the 1960s and were brought to this country by professionals and scholars Argentina. The goal of our research was to establish an epistemological path of the psychopedagogical clinic in Brazil to try to understand the scientific pillars that support it, in order to establish their bases. From an earlier survey of authors to be investigated, passed the stage of reading and analysis of these works. Our investigation followed by two-way analysis: the first was to construct an epistemology of psychopedagogical theory to practice. For this first pathway, however, the course of action turned out to be a bit confusing. From this difficulty, we started to investigate the various psychopedagogical practices and started a second analysis pathway, that means, we first analyzed the practices and only then thought of their theories. In this way we were able to trace a path from the epistemology of psychopedagogical Clinic in Brazil. We understand that by its nature of a new practice in matters of learning problems, and are very much dependent of psychology, pedagogy, psychoanalysis etc., psychopedagogy still has to give many steps in the direction of its epistemological affirmative.

2.

Key-words: Epistemology of the psychopedagogy. Practice and theory psychopedagogical. Interdisciplinary.

\section{Introdução}

Gostaríamos de relatar neste artigo algumas reflexões que estamos fazendo nesses últimos anos que se materializaram em um trabalho monográfico do primeiro autor sob a orientação do segundo. As reflexões que aqui apresentamos são concebidas, portanto, dessas duas vozes que se articulam e dialogam com tantas outras que têm o objetivo de compor este trabalho. 


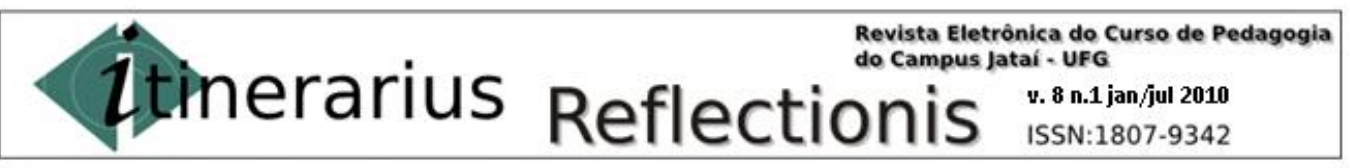

Tal como Bakhtin (1988), o que apresentamos aqui é a síntese da polifonia de vozes que compõem profissionais e pensadores da psicopedagogia clínica no Brasil. Procuramos compreender o espaço de epistêmico da psicopedagogia clínica brasileira tentando entender, a partir de suas práticas, a articulação das diversas ciências que as fundamentam. E, a partir disso, delineamos um perfil daquilo que concebemos como o espaço epistêmico da psicopedagogia, assim como postulamos alguns questionamentos que julgamos ser pertinentes na atual situação da psicopedagogia clínica no Brasil.

\section{O MÉTODO DE INVESTIGAÇÃO}

O cuidado com o conhecimento é um tema antigo, pois os gregos também tiveram preocupação sistemática e filosófica com as condições de formação de conhecimento (CARVALHO, 2001), predominando o tipo theoretiké, isto é, um tipo de conhecimento adquirido pela abstração, que vai além dos fenômenos empíricos. Os gregos admitiam, porém, outros tipos de conhecimento, o teckné (prático) que estava ligado ao trabalho e à execução de atividades necessárias para a vida. A confiança na metodologia escolhida surge quando o pesquisador age com inteligência, ética e coragem, como diz Santaella (2004) do topo de suas quase três décadas lidando com pesquisa.

A partir disso, passamos a considerar a seleção de alguns autores, sem os quais esta pesquisa não poderia se realizar, a saber: Beatriz Scoz (2004), Nádia Bossa (2000), Sara Paín (1999), Alícia Fernandez (1991), Jorge Visca (1985) e alguns outros que pretendemos expor ao longo do artigo. Mesmo diante desse seleto grupo, escolhemos, dentro de suas obras, aquelas que tratassem de questões conceituais em psicopedagogia, e só então pensamos na constituição epistemológica da psicopedagogia clínica brasileira.

Após a leitura desse material e discussão, fizemos a análise com o objetivo de encontrar alguns pilares da psicopedagogia clínica no Brasil. Nossa investigação seguiu para duas vias de análise: a primeira delas foi construir uma epistemologia da teoria à prática psicopedagógica. Por esta primeira via, contudo, o percurso se mostrou um pouco confuso devido à diversidade de teorias encontradas no campo da psicopedagogia clínica brasileira. Partindo dessa dificuldade, passamos a investigar as diversas práticas psicopedagógicas e a partir de uma segunda via analisamos as práticas e em seguida pensarmos em suas teorias.

Para essa jornada, escolhemos duas categorias: a primeira delas a prática dos profissionais em psicopedagogia. Procuramos investigar de que expediente se utilizam, buscando identificar os recursos técnicos empregados desde a fase de anamnese até a fase de intervenção propriamente dita. Essa primeira categoria de análise fundamenta-se do dizer de Piaget (1981) segundo o qual o discurso epistemológico de uma dada ciência deve ser tecido justamente por aqueles que a praticam. É pelo fieri, neste caso, pelo fazer psicopedagógico que as tramas epistemológicas podem ser elevadas à condição de discurso coletivo.

A segunda categoria de análise diz respeito às teorias que tentam explicar ou mesmo fundamentar a prática psicopedagógica, através do qual identificamos o norteador conceitual da prática desse profissional, quais as concepções de aprendizagem e os sujeitos que perpassam suas atividades. 


\section{A PRÁTICA DA PSICOPEDAGOGIA CLÍNICA NO BRASIL}

As práticas psicopedagógicas são relativamente novas no território brasileiro. Datam da década de 1960 e foram trazidas a esta pátria por profissionais e estudiosos argentinos (ANDRADE, 2004; FONTES, 2006). Desde então, elas vêm ganhando espaço nas questões educacionais principalmente naquelas que dizem respeito aos problemas de aprendizagem.

Segundo a Associação Brasileira de Psicopedagogia (ABPP, 2005), não existe uma prática padronizada e uniforme nas ações psicopedagógicas, "aquela que o profissional utiliza para ajudar seu cliente a aprender e ter sucesso é a melhor e a mais adequada. Cada indivíduo tem sua peculiaridade e assim deverá ser estudado". Identificamos uma gama de ações psicopedagógicas, todas com o objetivo de identificar e intervir nos problemas de aprendizagem.

Quando um profissional psicopedagogo é procurado, pretende-se que este diagnostique e intervenha na questão apresentada. O que ocorre é que a queixa, que geralmente parte da escola, aponta para os pais ou responsáveis algo que está obliterando a aprendizagem daquele aluno. Tal como destaca Weiss (1991, p. 96)

O objetivo básico do diagnóstico psicopedagógico é identificar os desvios e os obstáculos no modelo de aprendizagem do sujeito que o impedem de crescer dentro do esperado pelo meio social.

O princípio da ação psicopedagógica, na maioria das vezes, está marcado pela anamnese que consiste na identificação do problema de aprendizagem e a proposição de uma hipótese diagnóstica que dê conta do caso apresentado. Para a análise inicial, Weiss (2003) propõe alguns caminhos investigativos: a história das primeiras aprendizagens, a evolução geral, a história clínica, a história da família nuclear, a história da família ampliada e por fim, a história escolar (SALVARI; DIAS, 2006).

Um dos instrumentos para se efetuar tal percurso é formular um questionário de anamnese que procure levantar o maior número de informações, a fim de conseguir pistas das dificuldades encontradas no aprendente ${ }^{3}$. $\mathrm{O}$ uso recursivo do questionário procura focar a investigação por duas vias. Segundo Weiss (2003), a primeira seria a via horizontal que procura responder como o problema se apresenta hoje, ou seja, trata-se de procurar levantar um maior número de dados o mais abrangente quanto possível em que se possa verificar a dinâmica do suposto problema de aprendizagem.

A autora acrescenta outra via, o percurso vertical. É neste momento que se procura fazer um mergulho nas diversas histórias do sujeito. O psicopedagogo ao inquirir os pais ou o próprio aprendente faz um levantamento biográfico meticuloso, abrangendo desde sua vida de pré-concepção até seu momento atual. Acredita-se que essas informações possam desvelar possíveis entraves que estejam interferindo no processo de aprendizagem.

3 Aprendente: neologismo criado por Fernandez (1991). Significa sujeito em processo de aprendizagem. 


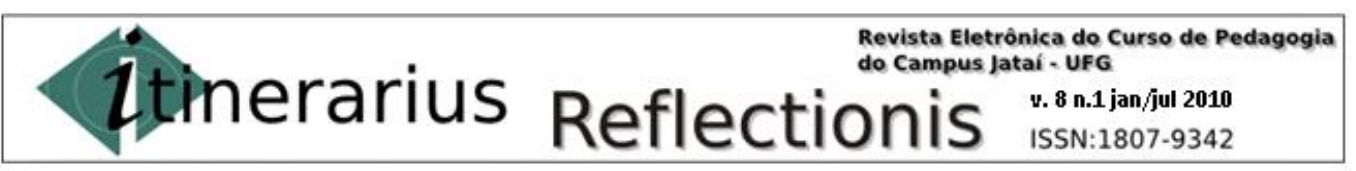

Após a escuta da queixa inicial e da fase de anamnese, passa-se à fase de avaliação propriamente dita. Bossa e Oliveira (1999) listaram uma série de avaliações que podem ser feitas com o sujeito, tais avaliações visam levantar alguma hipótese do problema de aprendizagem.

Uma estratégia utilizada é discutir a avaliação do sujeito através de suas produções gráficas por meio de desenhos; com isso procura-se perceber como a criança se organiza de forma espontânea frente ao material lúdico e gráfico, segue-se a esta observação a efetivação de um espaço onde se possa dar muita liberdade à criança para que fale como quiser (SCOZ, 2004).

Há ainda a possibilidade de se fazer uma avaliação com os aportes psicanalíticos. A observação em momento lúdico possibilita ao psicopedagogo observar as angústias e defesas que são mobilizadas pela situação de aprendizagem, pelo erro cometido, pela instrução e pela presença do psicopedagogo.

Seguem-se então sugestões de avaliação neuropsicológica. Neste momento, o psicopedagogo deve estar atento às funções motoras, às praxias orais, às funções acústico-motoras e às funções intelectuais do sujeito. Alia-se a isso um exame psicomotor. Para essa empreitada, o psicopedagogo deverá estar atento a uma série de particularidades do sujeito. Para tanto, o profissional necessitará observar: coordenação óculo-manual, coordenação dinâmica, controle postural (equilíbrio), controle do próprio corpo, organização perceptiva, linguagem e lateralidade. Há ainda algumas considerações, o psicopedagogo deve estar atento ás intenções comunicativas do sujeito, a expressão oral, a quantidade e a qualidade da fala, a produção articulatória etc.

Para compor a avaliação o profissional deve considerar dois tipos de avaliação: pedagógica e do nível operatório. No primeiro tipo de avaliação, procura-se verificar o desenvolvimento da leitura, o desenvolvimento da escrita, a aprendizagem matemática etc. Nessa oportunidade, o psicopedagogo pode também utilizar recursos lúdicos. Por exemplo, para a avaliação da leitura, os dados de anamnese se tornam importantes na medida em que a seleção dos textos a serem utilizados pode (e é bom que assim seja) fazer parte do rol de interesses do aprendente (RUSCHEL, 2006). No que diz respeito à avaliação matemática, esta pode se dar por meio de jogos em que se solicite ao sujeito que dê conta do somatório de pontos de uma partida disputada entre psicopedagogo e aprendente (NEGREIROS, 1999).

Quanto ao nível operatório segue-se o modelo clássico piagetiano no qual se procura investigar a complexidade estrutural do aprendente. Dependendo da idade do aprendente, o psicopedagogo poderá realizar provas de conservação de pequenos conjuntos discretos de elementos, de quantidade de líquido, de quantidade de matéria, de comprimento, de peso e de volume. Ainda podem ser realizadas, para avaliação do nível operatório, provas de mudança de critério (dicotomia), quantificação da inclusão de classes, intersecção de classes, seriação, combinação e permutação.

A intervenção psicopedagógica está diretamente relacionada com o resultado da avaliação. Assim, uma vez detectado o problema de aprendizagem, o psicopedagogo dispõe de técnicas de intervenção com o objetivo de ajudar o aprendente em sua limitação.

O sujeito poderá apresentar problemas com cálculos matemáticos, o que poderá ser classificado como acalculia ou discalculia, da mesma forma as dificuldades léxicas são classificadas como alexia ou dislexia. A essas dificuldades acrescentam-se: agrafia, disgrafia, disortografia, discaligrafia, dissintaxe ou ainda sintomas combinados.

Muitas técnicas têm como objetivo modificar a ação corporal do sujeito afastando aquilo que esteja dificultando seu aprendizado, ou mesmo, quando esta ação 


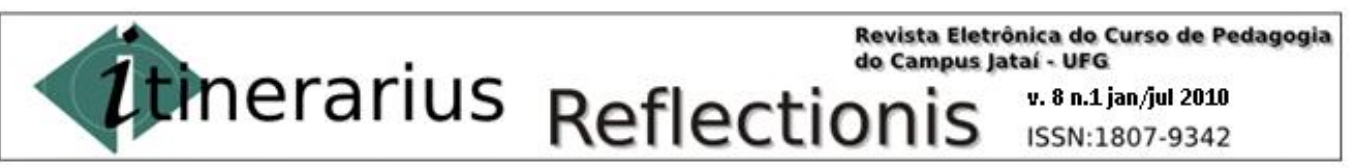

não é percebida pelo aprendente, procuram desfazer movimentos desnecessários que interfiram no momento da aprendizagem. Assim, por exemplo, o sujeito que possua uma qualidade gráfica comprometida pode fazer o treino da escrita com lápis triangular em um papel sensível à pressão da mão. O psicopedagogo intervém nos momentos em que perceba força desnecessária no ato da escrita. Também este pode intervir na postura geral global do sujeito, sugerindo-o posicionar-se de maneira adequada à tarefa solicitada, neste caso, a escrita.

Existe também uma série de exercícios gráficos desenvolvidos pela psicomotricista francesa Giselle Soubiran que visam ao aperfeiçoamento da mecanização da escrita. Esses exercícios trabalham freio inibitório na escrita, ajuste fino de precisão etc. Enfim, são práticas corporais que visam à melhoria da escrita do sujeito (LEVIN, 1995).

Se por outro lado o problema de aprendizagem se encontra na leitura, uma das técnicas utilizadas é convidar o aprendente a realizar desenhos, que podem ser feitos por meio da técnica de desenho livre, desenho cego e, a partir daí, pede-se que o sujeito elabore uma estória sobre sua criação e depois a leia para o profissional. Aqui, o psicopedagogo terá oportunidade de favorecer o treino de seleção de figura-fundo na seleção textual, poderá também propiciar a capacidade de análise e síntese do sujeito, uma vez que seja solicitado a recontação da estória alterando seu final, o que possibilita ao sujeito "brincar" com seu próprio texto.

Por sua vez, se as dificuldades apresentadas estão no nível matemático, há um conjunto de técnicas que favorecem a solução desse tipo de problema. O uso de jogos que requeiram do sujeito a realização de pequenas somas ou subtrações é largamente empregado. Acredita-se que, mesmo tendo de realizar tarefas matemáticas no espaço clínico, o sujeito pode ter sucesso em suas atividades, uma vez que essas tarefas estão inseridas em um momento lúdico, o que o afasta daquela situação convencional de sala de aula, onde se cumpre muitas vezes uma tarefa enquanto condição capital para sua promoção ou não de ano escolar.

Vemos o quanto são diversas as fontes de intervenção psicopedagógica, o que depende numa relação direta da formação inicial do psicopedagogo e leva-se também em consideração a singularidade do sujeito.

Com o propósito de estudar a aprendizagem e seus problemas, a Psicopedagogia procura relacionar outras áreas de conhecimento, a fim de realizar um trabalho interdisciplinar, contribuindo para a compreensão do processo, a orientação dos problemas decorrentes e também para melhorar a qualidade do ensino. (PASSERI, 2003, p.168).

Acredita-se que, não obstante a dislexia ter suas manifestações clássicas, a forma de intervir deve levar em consideração a particularidade de cada sujeito. Dentro dessa visão, não existe "o disléxico" assim como não existe "a forma ideal de intervenção para todos os disléxicos” (ABPP, 2005).

\section{A FUNDAMENTAÇÃO TEÓRICA DA PSICOPEDAGOGIA CLÍNICA}

Marcadamente duas grandes teorias são utilizadas pela psicopedagogia clínica brasileira (LANJONQUIÈRE, 2003; PAÍN, 1999; VISCA, 1985). Trata-se da teoria psicológica piagetiana, conhecida como Psicologia Genética, e da teoria psicanalítica, quer em sua origem freudiana ou em sua versão lacaniana. 
Fizemos essa distinção entre teorias porque epistemologicamente psicologia e psicanálise se diferem. Os aportes teóricos e as práticas psicanalíticas são de outra ordem dos daqueles da psicologia. Contudo, Paín (1999, p.13) defende a ideia de que certos aspectos da Psicologia Genética e da Psicanálise apontam para uma mesma direção. Apesar de afirmar que,

De um lado, a teoria genética da inteligência, e, de outro, a psicanálise, são precisamente irredutíveis, visto que uma se apóia sobre a lógica da ação, enquanto que a outra, sobre a realização do desejo, estando as condições da verdade, para cada uma delas, nas leis próprias a seus objetos.

A autora encontra três elementos que estão em consonância nestas teorias.

O primeiro deles é a noção de estrutura: tanto Piaget como Lacan defendem a ideia de ordenação do universo humano, através da qual é possível a obtenção de leis e propriedades dessa totalidade.

O segundo elemento é a noção de gênese. Ora, a questão da gênese em Piaget não apresenta qualquer dúvida, pois sua própria psicologia estava preocupada com a gênese do conhecimento e, portanto, do desenvolvimento da inteligência. Já em psicanálise, a autora afirma que se pode "considerar a psicanálise, de um modo superficial, como uma teoria genética, posto que ela recorre sempre, seja à origem da vida psíquica ou aos estágios do desenvolvimento da criança" (PAÍN, 1999, p.17).

O terceiro elemento discutido é a noção de inconsciente. Há neste último argumento uma inversão $\mathrm{O}$ inconsciente é uma das premissas da psicanálise, um dos fundamentos desta teoria, contudo, no que diz respeito à Psicologia Genética a pesquisadora apoia-se na compreensão de Piaget de que "o passado intelectual do indivíduo é, para si próprio, bem mais desconhecido que o passado sentimental, porque as fontes do primeiro devem ser procuradas nas coordenações das ações, que escapam, totalmente, à visão direta" (PIAGET apud PAÍN, 1999, p.20). Conclui que o inconsciente piagetiano é cognitivo, enquanto que o inconsciente freudiano é simbólico.

Os autores supracitados trabalham com bastante eloquência tanto a teoria da Psicologia Genética de Piaget como a Psicanálise, procurando fazer em suas obras uma apara das arestas dessas teorias, com o objetivo de fazê-las dialogar em torno de um objetivo comum: o sujeito com problemas de aprendizagem.

A questão não é nada fácil. Sabemos que o objeto da Psicanálise é diverso daquele da Psicologia Genética, assim como as condições em que a teoria psicanalítica surge são muito diversas das condições de Escola de Genebra. E por que então a insistência nessa dupla jornada? Qual o objetivo desses autores em querer compreender o aprendente em seus aspectos cognitivos e desejantes?

Uma das referências mais comuns que estes autores fazem pelo duplo interesse da conjugação Psicanálise e Psicologia Genética é a própria noção elaborada por Piaget (1989, p.227) quando este afirma que um dia as duas teorias se complementarão e darão espaço a uma só teoria que dê conta das questões cognitivas e simbólicas.

Em compensação estou persuadido que chegará o dia em que a psicologia das funções cognitivas e a psicanálise serão obrigadas a se fundir numa teoria geral que melhorará as duas corrigindo uma e outra, e é esse futuro, que é conveniente prepararmos, mostrando desde agora as relações que podem existir entre as duas. 


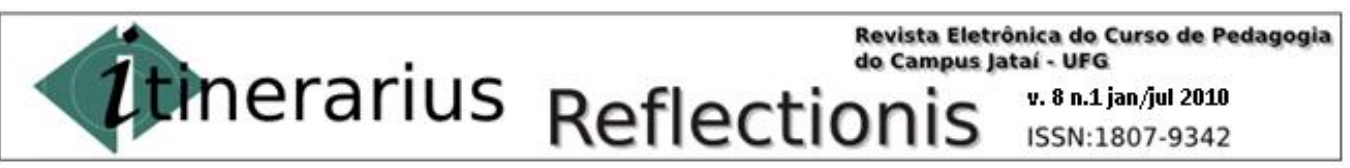

Contudo, a Psicanálise e a Psicologia Genética não são as únicas teorias que influenciam as práticas em psicopedagogia clínica no Brasil. Outras perspectivas psicológicas são a psicometria e a avaliação por testes projetivos. Trata-se de um recurso exclusivo de uso profissional dos psicólogos, mas aqueles psicopedagogos que têm como formação a graduação a psicologia o utilizam.

A psicometria é fundamentada em concepções sobre inteligência dentre as quais a Teoria do fator $g$ geral da inteligência de Charles Spearman e a teoria multifatorial de L. L. Thurstone. Já os testes projetivos são baseados na teoria psicanalítica, nestes há a pressuposição de que na atividade solicitada no processo de avaliação o aprendente poderá projetar seu estado psíquico sendo passível de avaliação por parte do psicopedagogo. Entretanto, Rubinstein (2004, p.227) estabelece uma crítica ao uso da avaliação do aprendente por meio de testagem psicológica.

(...) a psicometria utilizada para medir habilidades e competências é entendida como uma 'fotografia instantânea'. Hoje, uma parte significativa dos profissionais está mais interessada em pesquisar a zona de desenvolvimento proximal. Atualmente, a perspectiva de análise é oposta àquela dos primórdios dos estudos do fracasso escolar.

A autora destaca outro nível de avaliação da aprendizagem criado por L. S. Vigotski (2001). Este psicólogo criou o conceito de Zona de Desenvolvimento Proximal (ZDP) ao realizar estudos com crianças. Estas eram convidadas a realizarem tarefas de acordo com o grau de complexidade relativo às suas idades. Em um segundo momento, o pesquisador introduzia a presença de um sujeito mais capacitado com o objetivo de auxiliar a realização de tarefas mais complexas. O desempenho das crianças auxiliadas era superior àquele apresentado quando em atividades individuais. Tal fato o levou a acreditar na existência de um espaço de desenvolvimento que apontava para um sentido prospectivo. As crianças eram avaliadas não em relação ao seu passado, o que supostamente já haviam aprendido, mas em relação às potencialidades futuras que proporcionariam a resolução de problemas.

Talvez o que seja importante considerar, a partir dessas explicações, é que a ZDP não é uma estrutura e muito menos pode ser atestada por testes psicométricos, acerta Rubinstein. Neste sentido, pois, o que o psicopedagogo deve procurar perceber são os processos de interações infantis e as ZDP que ali emergem na dinâmica da aprendizagem.

Ainda no sentido da interação social, a psicopedagogia brasileira se apropria da teoria de Pichon-Rivière. Trata-se de uma teoria sistêmica que procura perceber o papel que o sujeito ocupa dentro de um grupo, sendo que este pode ser sua família, sua escola etc. Essa teoria exerceu uma forte influência nos estudos de Jorge Visca (1985) quando da elaboração da Epistemologia Convergente.

No tópico seguinte, discutiremos de que modo se dá a articulação das práticas em psicopedagogia clínica no Brasil com as teorias que lhes dão suporte. A partir desse confronto, poderemos esboçar o status do espaço epistêmico da psicopedagogia clínica brasileira.

\section{FORMAÇÃO EPISTEMOLÓGICA DA PSICOPEDAGOGIA CLÍNICA NO BRASIL.}

Abordamos, nos resultados desta pesquisa, a ação psicopedagógica desde a avaliação até a intervenção propriamente dita. Vimos como são inúmeras as práticas 
utilizadas, o que dificulta o estabelecimento um paradigma da clínica psicopedagógica no Brasil. Rubinstein $(2004$, p. 231) afirma que "não há como pretender unificar a prática psicopedagógica, pois ela depende das diferentes identificações teóricas e do estilo de cada profissional".

Vimos ainda que a fundamentação teórica da psicopedagogia clínica brasileira se dá pelo caminho da diversidade. São incontáveis as ciências que fundamentam as práticas, passando desde ciências da área da saúde como medicina e fonoaudiologia, seguindo seu curso, até a psicologia e a pedagogia.

Discutiremos todos esses achados considerando a seguinte citação de Lajonquière (2003, p. 130-131):

Dizer transdisciplinaridade no lugar de interdisciplinaridade não se mostra gratuito nem inócuo. O segundo termo pressupõe, necessariamente, uma operação de articulação teórica que nós descartamos por considerá-la inviável, na medida em que cada um dos campos teórico-práxicos considerados, constitui, em sentido estrito, uma noção de sujeito que não guarda relação alguma com a outra: sujeito epistêmico x sujeito do desejo (por sinal, que assim seja não é nenhum pecado). Isto determina que, assim como cada um desses campos amalgama-se em torno de uma noção particular de sujeito, o campo transdisciplinar que vislumbramos costura, por sua vez, uma nova noção - um novo objeto teórico construído com os retalhos dos anteriores. Terrorífica criatura? Apesar de que todo o empreendimento teórico, em certo sentido, não faça senão encarnar o espírito do Dr. Frankenstein por se valer também de retalhos, daí não decorre que, necessariamente, sejamos tão displicentes a ponto de montar o nosso monstro com os olhos na nuca. O sujeito epistêmico do construtivismo genebriano (bem como seu sujeito psicológico pós-70) e o sujeito do desejo inconsciente da psicanálise não podem ser, simplesmente costurados.

Seguindo essa linha, o autor se mostra ético quando procura realizar sua análise da psicopedagogia tomando certos cuidados para fugir de uma displicência irresponsável "a ponto de montar nosso monstro com os olhos na nuca".

O problema de ordem estética se não é mais agravante é, sem dúvida, mais notório. A bricolagem de retalhos de diversos corpos humanos causa um estranhamento a ponto das pessoas não conseguirem elaborar uma gestalt satisfatória. Quando falamos em gestalt satisfatória estamos nos referindo às leis da percepção: fechamento, continuidade, boa forma etc. O não fechamento dessa gestalt faz com que o homem não se reconheça homem, a criatura não se reconheça criatura, causando repúdio ao desconhecido.

Como reconhecer as diversas teorias que embasam o corpo teórico da psicopedagogia clínica brasileira? Será que a psicanálise reconheceria seu retalho naquele corpo? Será que Piaget encontraria a parte que lhe cabe nesta combinação? E quanto aos demais saberes (psicomotricidade, linguística, neurologia, neurociência, psicologia social, antropologia, sociologia etc)?

Se fizermos uma investigação mais acurada e minuciosa, veremos que só podemos dar um passo seguinte na compreensão do sujeito que procura a clínica se tivermos respondido às inquietações anteriores. Ou seja, se não tivermos bem claro qual o sujeito a ser investigado na clínica psicopedagógica e mais ainda, por quais meios investigar, estaremos fadados a acrescentar saberes em uma ordem exponencial aumentado ainda mais este conglomerado de pretensas contribuições nas dificuldades de aprendizagem. 


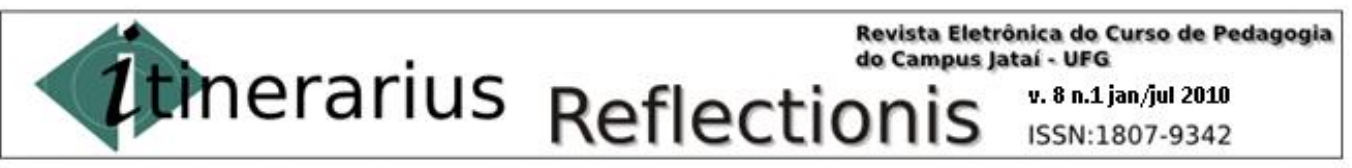

Faz-se necessária à psicopedagogia clínica brasileira, portanto, antes de qualquer coisa:

1. Recortar seu objeto de estudo;

2. Compreender epistemologicamente que teoria ou teorias dão conta desse objeto;

3. Verificar a consistência dessas teorias na compreensão da problemática envolvida no processo de aprendizagem;

4. Finalmente, harmonizar epistemologicamente os diversos pilares teóricos na clínica psicopedagógica.

Temos algumas indicações que podem auxiliar a definir a psicopedagogia, no sentido de configurar seu campo de investigação e seu objeto de estudo. A partir da visão fenomenológica, a psicopedagogia estabelece seu objeto de estudo, uma unidade vital no ato de conhecer a realidade, o ser cognoscente. Portanto, a psicopedagogia, com essa nova perspectiva, não percebe mais os alunos como partes isoladas, inteligência, emoção, psicomotricidade que são necessárias para aprender. O que temos é um sujeito, um ser que, se o dissecamos para melhor conhecê-lo, apenas o destruímos. Portanto, não faz sentido falar em inteligência ou afetividade como dimensões isoladas, mas como dimensões integradas por um sujeito, por um eu que se dedica a conhecer o mundo.

O passo seguinte é entender as teorias que dão suporte à psicopedagogia. Temos que observar o rigor epistemológico sob pena de aglomerarmos disciplinas muitas vezes opositivas entre si. Observamos que muitas práticas estão sob a ótica de teorias empiristas que visam a um ideal racionalista e que se autodenominam de construtivistas. Uma vez que se compreenda em que campo se circunscreve cada teoria, o psicopedagogo tem condições de verificar a consistência desse saber em sua prática. Com isso, consegue averiguar se esta ou aquela teoria pode realmente dar conta do problema de aprendizagem encontrado na clínica.

O recrudescimento da clínica acerca dos problemas de aprendizagem tornou-se algo importante uma vez que possibilitou se pensar sobre esse sujeito integrado; mas, dentro das práticas psicopedagógicas brasileiras, corre-se um sério risco. Parece que a psicopedagogia clínica do Brasil está ainda à sombra do substrato orgânico. Se não mais falamos de Disfunção Cerebral Mínima (DCM), diagnóstico muito comum no século passado, contemporaneamente focamos no distúrbio do déficit de atenção com ou sem hiperatividade. O ressurgimento desse tipo de discurso, que objetiva explicar o fracasso escolar, pode provocar um movimento nosográfico e uma pretensa fundação de uma psico-pedo-patologia das aprendizagens.

\section{CONSIDERAÇÕES FINAIS}

Tal como na tragédia de Édipo rei, a psicopedagogia clínica brasileira encontra-se em uma encruzilhada que pode determinar seu destino. Será que poderemos prosseguir com um ecletismo multi, pluri referenciado ou procuraremos consistência através de algumas delimitações teóricas que fundamentam as práticas da clínica psicopedagógicas?

Acreditamos na psicopedagogia e em suas práticas. A respeito de algumas problemáticas epistemológicas, sabemos que esta funciona "não por uma força misteriosa", mas porque a clínica psicopedagógica privilegiou um espaço onde os sujeitos que a procuram possuem a liberdade para aprender e para dizer o que sabem 
fazer. Mais que o espaço da sala de aula, a clínica psicopedagógica preza pelo sujeito cognoscente e suas vicissitudes, uma vez que o sujeito da aprendizagem pode mostrarse a si mesmo, não somente ao profissional do setting terapêutico.

Sendo assim, a partir de nossos estudos concluímos que nem tudo se presta a clínica psicopedagógica. Devemos observar os limites do que constitui o senso comum e as práticas científicas já configuradas no espaço das demais ciências. Com isso, estamos querendo afirmar que a não observação dessa premissa poderá conduzir a psicopedagogia à constituição mais próxima de dogmas do que de práticas com embasamento científico. Mesmo que esta não se constitua enquanto ciência e se configure mais como uma prática a serviço das questões de problemas de aprendizagem, a psicopedagogia não pode prescindir do rigor científico.

Ao entender que a psicopedagogia clínica no Brasil é uma prática multireferenciada, ou seja, é uma pragmática clínica dos problemas de aprendizagem, não seria melhor revermos as formações nos sentidos de alterarmos seus objetivos e optarmos pelas discussões dessas práticas ao invés de ouvirmos notícias sobre esta ou aquela teoria? Compreendemos que por seu caráter de uma nova prática nas questões de problemas de aprendizagem e, por ser altamente tributária da psicologia, da pedagogia, da psicanálise etc., a psicopedagogia ainda precisa se desenvolver mais no sentido de sua afirmação epistemológica.

\section{REFERÊNCIAS}

ANDRADE, M. S. de. Rumos e diretrizes dos cursos de psicopedagogia: análise crítica do surgimento da psicopedagogia na América - Latina. Cadernos de Psicopedagogia, São Paulo. v.3, n.6. p. 70-71, jun. 2004.

ASSOCIAÇÃO BRASILEIRA DE PSICOPEDAGOGIA (ABPp). Perguntas mais frequentes. Disponível em: <http://www.abpp.com.br/faq.htm>. Acesso em: 02 jul. 2005.

BAKHTIN, M. Marxismo e filosofia da linguagem. 4 ed. São Paulo: Hucitec, 1988.

BOSSA, N. A. A psicopedagogia no Brasil: contribuições a partir da prática. 2 ed. Porto Alegre: Artmed, 2000.

BOSSA, N. A.; OLIVEIRA, V. B. de (Orgs.). Avaliação psicopedagógica da criança de zero a seis anos. 9 ed. Petrópolis: Vozes, 1999.

CARVALHO, de. M. C. Metodologia científica, fundamentos e técnicas: construindo o saber. 11 ed. Campinas, SP: Papirus, 2001.

FERNANDEZ, A. A inteligência aprisionada: abordagem psicopedagógica clínica da criança e sua família. Porto Alegre: Artmed, 1991.

FONTES, M. A. Psicopedagogia e sociedade: história, concepções e contribuições. São Paulo: Vetor, 2006.

LAJONQUIÈRE, L. Para repensar as aprendizagens de Piaget a Freud: A (Psico)pedagogia entre o conhecimento e o saber. 12 ed. Petrópolis: Vozes, 2003. 
LEVIN, E. A clínica psicomotora: o corpo na linguagem. 2. ed. Porto Alegre: Artmed, 1995.

NEGREIROS, M. L. de M. Dividir, dividindo, divisão. In: RUBINSTEIN, E. R. (Org.) Psicopedagogia: uma prática, diferentes estilos. São Paulo: Casa do Psicólogo, 1999, p. 173-182.

PAÍN, S. A função da ignorância. Porto Alegre: Artmed, 1999.

PASSERI, S. M. R. R. A psicopedagogia nos distúrbios e dificuldades de aprendizagem. In: CIASCA, S. M (Org.) Distúrbios de aprendizagem: proposta de avaliação interdisciplinar. São Paulo: Casa do Psicólogo, 2003, p. 165-186.

PIAGET, J. Lógica e conhecimento científico. Porto: Civilização, 1981.

PIAGET, J. Problemas de psicologia genética. São Paulo: Abril Cultural, 1989.

RUBINSTEIN, E.; CASTANHO, M. I.; NOFFS, N. A Rumos da psicopedagogia brasileira. Revista da Associação Brasileira de Psicopedagogia, São Paulo. v. 21, n.66. p. 225-238, jun. 2004.

RUSCHEL, S. P. Ler e escrever: o trabalho com autoria na clínica. In: RUBINSTEIN, E. R. (Org.) Psicopedagogia: fundamentos para a construção de um estilo. São Paulo: Casa do Psicólogo, 2006, p. 303-324.

SALVARI, L. de F. C.; DIAS, C. M. de S. B. Os problemas de aprendizagem e o papel da família: uma análise a partir da clínica. Estudos de Psicologia, Campinas. v.23, n.3. p. 251-259, jul/set. 2006.

SANTAELlA, L. O método anticartesiano de C. S. Pierce. São Paulo: Editora UNESP, 2004.

SCOZ, B J. L. Psicopedagogia e realidade escolar: o problema escolar e de aprendizagem. Petrópolis: Vozes, 2004.

SILVA, M. C. A. e. Psicopedagogia: em busca de uma fundamentação teórica. Rio de Janeiro: Nova Fronteira, 1998.

VIGOTSKI, L. S. Obras escogidas, Pensamiento y lenguaje. 2 ed. Tomo II. Madrid: Visor, 2001

VISCA, J. Clínica psicopedagógica: epistemologia convergente. Porto Alegre: Artmed, 1985.

WEISS, M. L. L. Reflexões sobre o diagnóstico psicopedagógico. In: SCOZ, B. J. L.; BARONE, L. M. C.; CAMPOS, M. C. M.; MENDES, M. H. (Orgs.) Psicopedagogia: contextualização, formação e atuação profissional. Porto Alegre: Artmed, 1991. p. 89102. 


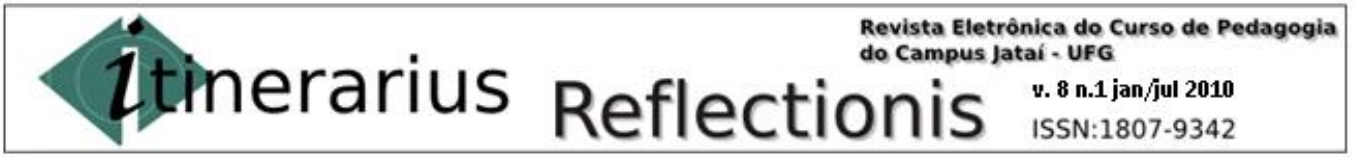

WEISS, M. L. L. Psicopedagogia clínica: uma visão diagnóstica dos problemas de aprendizagem escolar. 10 ed. Rio de Janeiro: DP\&A, 2003. 